\title{
PERSONAGENS ESCRITORES E A HISTÓRIA EM O ANO DA MORTE DE RICARDO REIS, DE JOSÉ SARAMAGO E EM LIBERDADE, DE SILVIANO SANTIAGO
}

\author{
Juliana Prestes de Oliveira ${ }^{1}$ \\ Raquel Trentin de Oliveira ${ }^{2}$
}

Resumo: Neste trabalho, realizamos uma análise comparativa entre as obras O ano da morte de Ricardo Reis (1984), do escritor português José Saramago, e Em liberdade (1981), do escritor brasileiro Silviano Santiago, na tentativa de melhor compreender como está sendo construída a literatura contemporânea brasileira e portuguesa e que transformações ela sofreu com o passar dos anos. A partir dessa aproximação, podemos perceber pontos semelhantes e distintos entre os romances, atentando para o modo como cada autor elabora sua narrativa, quais as estratégias linguísticas, temas e abordagens utilizadas. No decorrer da pesquisa, percebemos que ambos os autores se utilizam de personagens escritores, como Graciliano Ramos, Ricardo Reis, Fernando Pessoa, entre outros, e que, por meio do relato da história de vida dos protagonistas, temos acesso a uma versão diferente da História de Portugal e do Brasil durante os regimes opressores que estavam vivenciando, bem como à história da Literatura de ambas as nações. Além disso, à medida que Saramago e Silviano possibilitam que outros personagens, das mais diversas classes, tenham a sua voz ouvida, apresentam versões diferentes dos fatos históricos, favorecendo o questionamento e a dúvida perante os discursos até então dados como verdadeiros. Ao lermos os relatos dos personagens escritores e ao analisar o modo como Saramago e Silviano tecem seus romances acabamos por entender melhor alguns aspectos do momento histórico dessas nações e algumas das transformações que atingiram à arte literária.

Palavras-chave: História. Literatura. Personagens escritores.

Abstract: In this paper we realized a comparative analysis of the novel $O$ ano da morte do Ricardo Reis (1984), by portuguese writer José Saramago, and Em liberdade (1981), by brazilian writer Silviano Santiago, in an attempt to better understand how it is being built Brazilian and Portuguese literature and contemporary transformations it has undergone over the years. From this approach, we can see similar and different points between novels perceiving how each author constructs his narrative, which language strategies, themes and approaches used. During this study we perceived that both authors use characters from writers like Graciliano Ramos, Ricardo Reis, Fernando Pessoa among others, and that by reporting the life story of the protagonists we have access to a different version of history of Portugal and Brazil during the oppressive regimes that were experiencing as well as the history of literature of

\footnotetext{
${ }^{1}$ Mestranda em Estudos Literários do Programa de Pós-Graduação em Letras Curso de Letras da UFSM. E-mail: jprestesdeoliveira@gmail.com

${ }_{2}^{2}$ Professora Doutora do Mestrado em Letras da UFSM.
} 
both nations. Moreover, as Saramago and Silviano possible other characters from different classes have your voice heard, we have different versions of historical facts favoring the questioning and doubt before the speeches so far as real data. As we read the stories of the characters and writers examine how Saramago and Silviano weave his novels just by better understanding some aspects of the historical moment of these nations and some of the transformations that reached the literary art.

Keywords: History. Literature. Writers characteres.

\section{INTRODUÇÃO}

A literatura além de ser uma expressão de arte e de sentimentos, também é utilizada como forma de denúncia, crítica e um meio pelo qual é possível conhecer mais sobre a história de nossa sociedade. A literatura faz parte da história humana, e conforme a humanidade se modifica a literatura da mesma forma sofre processos de transformações. Na contemporaneidade tanto o homem, quanto a própria literatura estão olhando para si e pensando a sua condição. O sujeito contemporâneo está em busca da sua identidade nessa sociedade fragmentada na qual estamos vivendo. Destarte, muitas vezes o sujeito que se mostra reprimido pela história, pelo discurso e pela própria sociedade, fica à margem desta. Assim, a literatura vem como um meio de permitir que esses sujeitos possam ser vistos. Nela a desconstrução do discurso é ferramenta essencial para revelar a subjetividade que os personagens carregam.

A partir disso, o trabalho aqui proposto procura mostrar como os escritores José Saramago e Silviano Santiago abordam essa questão, além de investigar o modo como esses escritores utilizam-se dos personagens escritores para retratar a história de Portugal e do Brasil.

Silviano Santiago, no romance Em liberdade (1981), coloca-se no lugar do escritor Graciliano Ramos, e expõe um sujeito reprimido pela história, pelo discurso e pela sociedade. Para reconstituir um importante período histórico brasileiro, mais precisamente o ano de 1937, o autor utiliza os recursos próprios à metaficção historiográfica. Esse retorno ao passado possui um olhar crítico, que tenta desconstruir e desmascarar os vários discursos que estão 
inevitavelmente associados, de forma intrínseca, à situação histórica da sociedade, além de verificarmos a transformação da literatura nacional.

Do mesmo modo, José Saramago, no romance $O$ ano da morte de Ricardo Reis (1984), utiliza o escritor Fernando Pessoa e, principalmente, o heterônimo Ricardo Reis. É por meio deles que Saramago nos apresenta a situação de Portugal e também nos faz refletir sobre a literatura.

O jogo literário efetuado por Saramago e Santiago é ainda mais profundo quando percebemos que seus livros podem também retratar, além da época vivida pelos personagens, a época dos próprios escritores. Focando nos regimes opressores que cada país passou ou estava passando, no caso do Brasil Silviano Santiago vivia a Ditadura Militar Brasileira. Nessa perspectiva, as obras expressam os sentimentos e sensações dos escritores. Desse modo, os escritores criaram uma relação entre o ficcional e o histórico, construindo textos reflexivos acerca dos acontecimentos do passado, com caráter crítico e denunciador, revendo os acontecimentos históricos e convidando o leitor a ser mais atento aos discursos que lhe são apresentados.

\section{PERSONAGENS ESCRITORES E A HISTÓRIA}

Ao longo dos estudos acerca da literatura, percebemos que ela mantém uma proximidade com os acontecimentos da História da sociedade, da humanidade. E por isso, muitas obras trazem em seu enredo relatos de fatos históricos que realmente aconteceram. Algo que há em comum entre muitas dessas obras, é o fato de sua produção, ou publicação, ocorrer após um grande episódio histórico, que marcou a população.

É exatamente isso que encontramos nas obras Em liberdade, publicado em 1981, pelo escritor Silviano Santiago e $O$ ano da morte de Ricardo Reis, publicado em 1984, pelo escritor José Saramago. Ambos os autores procuram voltar a sua atenção, o seu enredo, aos fatos que aconteceram no Brasil e em Portugal e que marcaram esses países, deixando em seu povo cicatrizes que sobrevivem à corrosão do tempo, e às inúmeras tentativas de apagamento desses episódios. No caso da obra de Silviano Santiago, ele retrata três épocas do Brasil e três regimes opressores que vigoraram em nossa nação: a 
época da Inconfidência Mineira, O Golpe de Estado e o governo de Getúlio Vargas, em 1930, e a época vivida por Santiago que era a Ditadura Militar de 1964. Já na obra de José Saramago é abordado o período de governo de António de Oliveira Salazar, e a sua ditadura, em Portugal, além de mostrar como estava a situação política em vários países da Europa.

Os autores revisitam o passado histórico de seus países e mostram a $H(h)$ istória através de uma perspectiva diferente. Para isso, Santiago e Saramago se utilizam de personagens escritores, Graciliano Ramos, José Lins do Rego e Cláudio Manuel da Costa, no romance Em Liberdade; e Ricardo Reis e Fernando Pessoa, no romance de $O$ ano da morte de Ricardo Reis.

Apesar de haver esse retorno ao que aconteceu em cada nação, não há a destruição da História e do passado, mas uma reavaliação e um questionamento crítico acerca do que aconteceu na sociedade, buscando ouvir as experiências e relatos dos excluídos, daqueles que sofreram na pele com a ditadura, como é o caso do personagem Graciliano Ramos; daqueles que viam o que estava acontecendo de fora, como o personagem Ricardo Reis, que não estava envolvido nos acontecimentos políticos do país. Assim, está surgindo uma forma relativamente diferente de produzir literatura, algo capaz de fazer o leitor um indivíduo mais reflexivo, capaz de identificar aquilo que está nas entrelinhas e subentendido nos textos.

A partir disso, percebemos que há vários pontos em comum nessas duas obras, por isso, "[...] a comparação possibilita a esse tipo de estudo literário uma exploração adequada de seus campos de trabalho e o alcance dos objetivos a que se propõe" (Carvalhal, 1998, p. 7), ou seja, a comparação desses romances permitiria traçar um paralelo do que aconteceu e estava acontecendo no Brasil e em Portugal na mesma época, além de analisarmos como a literatura de cada país estava se modificando, os rumos que essa estava tomando.

Um dos pontos em comum encontrado em $O$ ano da Morte de Ricardo Reis e Em liberdade, que é utilizado pelos escritores para fazer essa volta ao passado, é o uso de várias vozes, dando oportunidade para o marginalizado falar e, assim, temos acesso às inúmeras versões do mesmo fato, e dessa forma conseguimos reavaliar a $\mathrm{H}(\mathrm{h})$ istória que até então temos como oficial, 
verdadeira e imutável. Além dessa estratégia, esses escritores envolvem seus leitores com narrativas cheias de comentários, notas de rodapés e acontecimentos, locais e personagens históricos que realmente existiram, na tentativa de convencer o leitor sobre o enredo e, assim, mostrar que devemos estar atentos aos discursos aos quais somos expostos, pois há sempre alguém querendo nos convencer de algo.

Tanto no romance de Santiago como no de Saramago, encontramos a metaficção historiográfica, que, segundo Linda Hutcheon (1991), são obras literárias que abordam temas e personagens históricos com tramas e personagens fictícios e que ao misturarem em suas narrativas textos históricos e literários, os escritores mostram ao leitor discursos desconhecidos, contribuindo na formação de um receptor capaz de realizar análises mais profundas dos discursos. É a literatura falando da História e da história, construção da própria literatura.

Hutcheon (1991, p. 64) ainda enfatiza que "[n]a metaficção historiográfica não há nenhuma pretensão de mimese simplista. Em vez disso, a ficção é apresentada como mais um entre os discursos pelos quais elaboramos nossas versões da realidade". Desta maneira, entendemos que a ficção é uma criação humana que se dá por meio da linguagem, do discurso, e como o discurso histórico também se constitui por meio da linguagem ele também pode ser a elaboração de apenas uma versão da realidade, de um ponto de vista, e que geralmente esse ponto de vista é daqueles que detém o poder.

Assim, nesses textos há uma preocupação com a construção da linguagem, levando-nos a questionar e refletir sobre os acontecimentos do passado. Podemos perceber o uso desse mecanismo quando Silviano Santiago e José Saramago envolvem em suas obras personagens fictícios e históricos e o momento histórico que esses vivenciaram, além de mostrar como a literatura estava se constituindo. Como no excerto de Em liberdade, em que o personagem Graciliano Ramos fala sobre escrever algo que contasse o que passou, denunciando os poderosos, revelando, assim, aquilo que era escondido pelos discursos oficiais: 
Outros mais audaciosos, não satisfeitos com as minhas narrativas orais [...] exigiam que o fizessem por escrito. Seria o documento definitivo contra a caça dos comunistas no Brasil. [...] finalmente teríamos o retrato fiel da intolerância política dos poderosos por alguém que a tinha sofrido na própria pele (Santiago, 1994, p. 59).

Destarte, há a denúncia através da voz daquele que sofreu com as opressões do governo de 1930, construindo uma nova versão da história, o que percebemos é que esses romances põem "[...] a nu o não-dito por trás do que foi dito, buscar o silenciado (reprimido) sob o que foi falado" (Santos, 2004, p. 71). Ademais, esse excerto também retrata a época que o Brasil passava pela ditadura militar de 64, período que Santiago estava vivendo e publicou esse romance, apesar de estar falando diretamente de outro tempo - 1930 podemos dizer que ele utiliza isso também para denunciar os horrores cometidos durante a ditadura militar de 1964.

Além de denunciar a repressão cometida pelo governo de Getúlio Vargas, Ramos nos revela a desvalorização da literatura e do escritor no Brasil:

[n]ão existe, para mim, outra maneira que não essa de ganhar dinheiro no Rio de Janeiro. [...] Meu cargo era público e estadual: não se pode pedir transferência para o Rio de Janeiro. Sei escrever; gosto de literatura. Queria escrever romances e viver deles. A literatura não dá dinheiro no Brasil (Santiago, 1994, p. 193).

$\mathrm{O}$ ato de escrever sobre um período de repressão, em que a liberdade de expressão não é permitida, é uma maneira de não deixar que esse acontecimento caia no esquecimento e, dessa forma, isso seja repensado, seja exposto e não se repita. Ademais, para o personagem Graciliano Ramos escrever sobre o que ele passou era uma forma de enfrentar tudo o que viveu: "[o] único motivo [...] que vejo no momento para poder deitar as minhas frases no papel é que quero não sentir o meu corpo. [...] elas camuflam um corpo dolorido que não quer pensar nas dores sofridas que castigam os sentidos e a memória" (Santiago, 1994, p. 22).

A metaficção historiográfica na obra $O$ ano da morte de Ricardo Reis também é apresentada por meio dos personagens, sendo eles Ricardo Reis e Fernando Pessoa. Através deles, descobrimos que Portugal está passando pela ditadura de Salazar e também sabemos o que está acontecendo nos 
países vizinhos, como quando Reis conversa com um funcionário do hotel sobre a situação política da Espanha: "[...] três famílias espanholas [...] vêm fugidas [...] por causa de terem os comunistas ganho as eleições, Não fora os comunistas, foram as esquerdas, [...] Até os jornais falam disso" (Saramago, 1988, p. 156). José Saramago expõe o cenário político de alguns países europeus, assim como Em liberdade, e também revela como os pensadores e escritores discutiam a literatura da época, como no trecho em que Fernando Pessoa e Ricardo Reis falam sobre o efeito que os tempos de ditadura causam nos textos, como isso pode influenciar nas obras, e como esses são mais intensos durante os regimes de opressão, pois é através desses que os autores conseguem expor suas ideias, através das entrelinhas: "[...] aqueles intelectuais que se sentem encarcerados nos regimes de força, mesmo quando essa força é mental, como a que dimana Salazar, esquecem-se de que a produção intelectual se intensificou nos regimes de ordem" (Saramago, 1988, p. 333).

Outro ponto em comum entre esses dois romances é, como citado anteriormente, o uso de várias vozes. Podemos dizer que isso é uma maneira de mostrar aos leitores os vários discursos, pontos de vista e perspectivas, referentes ao mesmo acontecimento, analisando o ponto de vista do opressor e do oprimido, pois, "[...] todos os grupos têm o direito de falar por si mesmo, com sua própria voz, e de terem aceita essa voz como autêntica e legítima" (Harvey, 2012, p. 52).

No romance de Silviano Santiago essas vozes são os personagens, o principal é a de Graciliano Ramos, através do qual temos acesso mais profundo à situação em que se encontra nosso país e de como o Estado visa o crescimento daqueles que pertencem a uma classe abastada, como exemplo há o seguinte trecho: "O progresso, no Brasil, apenas melhora as condições de vida de quem já as tem boas" (Santiago, 1994, p.160). Ele ainda fala sobre o que vivenciou e como as pessoas eram tratadas caso suas ideologias fossem contrárias às do governo:

[e]u mesmo fui vítima dessas forças ocultas. Fiquei quase um ano inteiro preso; tenho os diversos membros da minha família dispersos pelos quatro cantos; fui enviado como um saco de batatas para 
lugares terríveis, e no final descobre que não tem existe ordem alguma de prisão contra a minha pessoa. (Santiago, 1994, p. 87)

Também temos a voz de José Lins do Rego e Heloísa que, em diversas passagens, alegam que o Brasil está um caos, que todos os acontecimentos giram em torno dos interesses de quem está no comando, e que esses estão camuflados atrás da ideologia de que tudo é pelo bem do país. Eles também denunciam que qualquer sujeito pode ser mandado para a prisão sem motivos reais, como podemos ver na fala de José Lins do Rego: "Graça, você precisa compreender que este país é uma bagunça geral. Nada aqui se sustenta dentro de uma ética rigorosa. É sempre um jogo de interesse vergonhoso, mesquinho e camuflado" (Santiago, 1994, p.139); e na fala de Heloísa: "[e]ssa esculhambação brasileira é péssima. [...] porque um ministro pode mandar uma pessoa com quem conversa para a prisão sem motivo algum a não ser os que possam passar pela sua cabeça desvairada" (Santiago, 1994, p. 141).

Outra voz importante que aparece no romance, e que também apresenta um dos pontos de vistas da situação do Brasil, é a dos jornais que circulavam na época, pois esses tinham conteúdos semelhantes e raramente manifestavam-se contra o governo, como vemos na fala de Ramos: "[...] não há diferença: o que sai aqui, sai acolá. Se o leitor tiver interessado em notícias referentes a indivíduos isolados, aí sim, jornais e revistas diferem. Cada um tem seu próprio time quando chega à banca" (Santiago, 1994, p. 78). O protagonista também nos revela que os meios de comunicação que divulgassem qualquer coisa contra o governo, estariam correndo o risco de serem calados: "[a] Careta continua a ser o jornal que mais luta contra o espírito de golpe está presente [...] vai tecendo um ácido comentário crítico à atuação do presidente na luta sucessória. Temo pelo futuro da revista" (Santiago, 1994, p. 92, grifo do autor).

No romance de José Saramago, uma dessas vozes é a do narrador, é através do que ele conta que conhecemos um pouco da história de Portugal, como verificamos no seguinte excerto, que fala sobre o surgimento de Salazar: “[...] o aparecimento do professor António de Oliveira Salazar, há oito anos, [...] para salvar o seu país e o nosso país do abismo, para restaurar, para lhe impor 
uma nova doutrina" (Saramago, 1988, p. 298). É também por meio dele, que sabemos com mais precisão o quadro político de alguns países da Europa, como era caso da Espanha: "[...] a direita tinha ganho em dezassete províncias, mas, contados os votos todos, viu-se que a esquerda elegera mais deputados [...]. Começaram a correr boatos de estar em preparação um golpe militar" (Saramago, 1988, p. 153).

Além do narrador, temos a visão do personagem Fernando Pessoa que conta para Ricardo Reis o que aconteceu no país enquanto Reis esteve no Brasil: "[l]embro-me de ler, nos meus últimos dias, umas notícias sobre essa revolução, foi uma coisa de bolchevistas, creio. [...] Aqui em Portugal também tem havido umas revoluções" (Saramago, 1988, p. 81). Ele ainda expõe sua opinião sobre Salazar quando Reis pergunta quem é esse Salazar: "[é] o ditador português, o proctetor, o pai, o professor, o poder manso, um quarto de sacristão, um quarto de sibila, um quarto de Sebastião, um quarto de Sidónio" (Saramago, 1988, p. 278).

Por mais que Ricardo Reis seja o heterônimo de Fernando Pessoa que menos engajamento político possui, nessa obra de Saramago ele também nos revela várias coisas que a história oficial esconde e expõe suas reflexões sobre o que ele está vendo, e desse modo temos a visão de alguém que está fora de todo esse processo político e repressor, como exemplo temos: "[e]ste país está um desmazelo, os barcos que vão para a água antes do tempo, os presos que se somem, os carteiros que não entregam as cartas, os varredores, enfim, dos varredores não há nada a dizer" (Saramago, 1988, p. 342). Através dele vemos as atitudes e comportamentos da polícia, o modo que tratavam qualquer um que pudesse trazer algum tipo de perigo ao regime vigente. No caso de Reis, ele recém havia chegado do Brasil e poderia ter tido contato com algum revolucionário: "[a] polícia deve ter pouco o que fazer, para assim perder tempo com quem não tem culpas e nem se prepara para tê-las" (Saramago, 1988, p. 331). Ademais, ele procura se informar através do que dizem os jornais e a partir do que lê tece sua opinião, levando o leitor também a refletir sobre o que dizem os discursos: "tenho que acreditar que é verdade o que eles me dizem, um jornal não pode mentir, seria o maior pecado do mundo" (Saramago, 1988, p. 388). 
A construção da história de Portugal não fica apenas nas vozes de Fernando Pessoa e de Ricardo Reis, várias vezes reportagens de jornais traziam reportagens sobre o que acontecia em Portugal e nos países vizinhos, como no excerto: "escrevem-se nos jornais [...] sobre a derrocada dos grandes Estados, o português, o nosso, afirmará a sua extraordinária força e a inteligência reflectida dos homens que a dirigem" (Saramago, 1988, p. 85). Do mesmo modo que os jornais nos davam o panorama histórico do país, isso também ocorre por meio da fala da camareira Lídia, que conversa com Reis sobre o que está acontecendo, dando sua opinião ou falando sobre o que ouve de outros, principalmente seu irmão: "o meu irmão diz é que não se deve fazer sempre fé no que os jornais escrevem" (Saramago, 1988, p. 388).

A polifonia de vozes no romance de José Saramago não se restringe somente a esses personagens e também não foca somente as opiniões contrárias ao governo, o que deixa o romance ainda mais rico no que se refere às opiniões e versões dos fatos, dando um leque de possibilidades para o leitor refletir. Uma das opiniões que defende as decisões tomadas por Salazar é a do Dr. Sampaio, pai de Marcenda: "[a] nós o que nos vale, meu caro doutor Reis, neste cantinho da Europa, é termos um homem de alto pensamento e firme autoridade à frente do governo e do país" (Saramago, 1988, p. 137); outro que defendia o governo era o Dr. Adjunto, que interrogava Ricardo Reis sobre o que ele fazia no Brasil e com teve contato: "[o] governo da Ditadura Nacional pôs o país a trabalhar, [...]Há patriotismo, dedicação ao bem comum, tudo se fez para a nação" (Saramago, 1988, p. 192).

A utilização dessas vozes, principalmente a de personagens escritores como protagonistas, recurso utilizado por Santiago e Saramago, além de propiciar um retorno ao passado na busca de verdades escondidas, por versões diferentes acerca do mesmo acontecimento, também traz à tona relatos daqueles sujeitos silenciados pela história, bem como apresenta discussões e reflexões acerca da literatura e da sua formação. Podemos dizer que essa estratégia contribui para se produza uma literatura ainda mais capaz de fazer com que o leitor se torne atento aos discursos e de refletir sobre as inúmeras informações que recebe. 
Ambas as obras tratam dessa busca pela formação de um leitor que não seja facilmente manipulado, capaz de questionar os discursos que lhe são expostos, tornando-se sujeito crítico e pensante. Essa preocupação com a formação do leitor pode ser vista nos trechos a seguir:

\begin{abstract}
Assim como o escritor se interessa pelo alargamento das suas fronteiras linguísticas, também o leitor tem de trabalhar nesse sentido se quiser acompanhar o romancista, lendo sua obra. Dessa forma terá acesso a um pensamento diferente do seu. Terá um melhor conhecimento do outro (Silviano, 1994, p. 121)

Um homem deve ler tudo, um pouco ou o que puder, não se the exija mais do que tanto, vista a curteza das vidas e a prolixidade do mundo. Começará por aqueles títulos que a ninguém deveriam escapar, os livros de estudo, assim vulgarmente chamados, como se todos não o fossem, e esse catálogo será variável consoante a fonte do conhecimento aonde se vai beber (Saramago, 1988, p. 141)
\end{abstract}

Assim, por meio da comparação, vimos que os romances Em liberdade e $\mathrm{O}$ ano da morte de Ricardo Reis têm vários aspectos em comum e que não são vazias de significados. Elas trazem inúmeros discursos e relatos existentes sobre o mesmo fato, dando oportunidade de fala àqueles que não estão no centro e dessa forma fazer com que o leitor reflita sobre o que está vendo e passe a questionar o que the é apresentado como verdade, desenvolvendo sua capacidade crítica e de formação de opinião. Além disso, os escritores constroem um jogo literário com os personagens Graciliano Ramos e Ricardo Reis, aproximando a ficção da realidade, conduzindo os leitores à reflexão a respeito da elaboração de textos, tanto os literários, quanto os discursos da $H(h)$ istória.

\title{
3. CONSIDERAÇÕES FINAIS
}

A partir dessa análise, percebemos que os romances $E m$ liberdade e $O$ ano da morte de Ricardo Reis encaixam-se nas principais características da metaficção historiográfica, principalmente por dialogar criticamente com a (H)história, através das inúmeras vozes, inclusive do excêntrico e marginalizado, e daqueles que vivenciaram intensamente os fatos. Também podemos dizer que essas obras demonstram que os discursos são carregados de intenções e subjetividades, eles apresentam a maneira utilizada por aqueles 
que estão no poder para manipular o discurso. Porém, não há a intenção de destruir ou negar a História, o que se pretende é revisitar o passado, analisar cuidadosamente todos os acontecimentos de uma forma mais crítica. Para tanto, esses romances exigem um leitor mais reflexivo e analítico, atento ao que está nas entrelinhas do texto. $E$ isso, contribui para formar sujeitos questionadores diante das informações dadas como verdadeiras e incontestáveis.

\section{REFERÊNCIAS}

CARVALHAL, Tania C. Literatura Comparada. São Paulo: Ática, 1998.

HARVEY, David. Condição pós-moderna: uma pesquisa sobre as origens da mudança cultural. Tradução Adail Ubirajara Sobral e Maria Stela Gonçalves. 21. ed. São Paulo: Loyola, 2011.

HUTCHEON, Linda. Poética do Pós-Modernismo: história - teoria - fiç̧ão. Tradução Ricardo Cruz. Rio de Janeiro: Imago, 1991.

SANTIAGO, Silviano. Em Liberdade. Rio de Janeiro: Rocco, 1994.

SANTOS, Jair Ferreira. O que é Pós-moderno. São Paulo: Brasiliense, 2004.

SARAMAGO, José. 0 ano da morte de Ricardo Reis. São Paulo: Companhia das Letras, 1988. 